\title{
An extremely uncommon case of pancreatic extragastrointestinal stromal tumor in a 53-year-old female patient
}

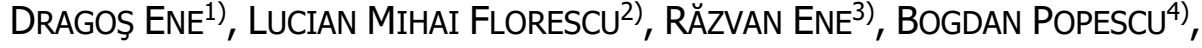 \\ IOANA ANDREEA GHEONEA²) \\ 1) Department of General Surgery, Carol Davila University of Medicine and Pharmacy, Bucharest, \\ Romania \\ 2) Department of Radiology and Medical Imaging, University of Medicine and Pharmacy of Craiova, \\ Romania \\ ${ }^{3)}$ Department of Orthopedics and Traumatology, Carol Davila University of Medicine and Pharmacy, \\ Bucharest, Romania \\ 4) Department of ENT, Carol Davila University of Medicine and Pharmacy, Bucharest, Romania
}

\begin{abstract}
Gastrointestinal stromal tumors (GISTs) are the most frequently encountered mesenchymal tumors that develop anywhere along the gastrointestinal (GI) tract, but they account for less than $1 \%$ of all GI tumors. However, GISTs can also develop outside the GI tract. They are referred to as extragastrointestinal stromal tumors (EGISTs) and represent around 5-10\% of all GISTs. In this latter case, the tumor itself is not connected to the $\mathrm{GI}$ tract and can affect the omentum, mesentery, and retroperitoneum. EGISTs can also originate from the pancreas, but they are extremely uncommon. It is estimated that pancreatic EGISTs account for about $5 \%$ of all EGISTs, with around 30 cases being reported in the literature so far. The current report presents an extremely rare case of pancreatic EGIST encountered in a 53-year-old woman with no remarkable personal or family medical history. Surgical resection of the pancreatic head tumor through pancreaticoduodenectomy using Whipple procedure combined with negative resection margins and adjuvant Imatinib mesylate treatment led to a favorable postoperative evolution. The follow-up at six months after surgery did not reveal any malignant changes
\end{abstract}

Keywords: gastrointestinal stromal tumor, pancreas, extragastrointestinal stromal tumor, pancreaticoduodenectomy, spindle cell.

\section{ㅁ Introduction}

Gastrointestinal stromal tumors (GISTs) are the most frequently encountered mesenchymal tumors that develop anywhere along the gastrointestinal (GI) tract, but they account for less than $1 \%$ of all GI tumors [1-3]. The two most common sites are represented by the stomach $(50$ $60 \%)$ and the small bowel (30-40\%). The rest of the GI tract is affected to a much lesser extent $[4,5]$. However, GISTs can also develop outside the GI tract. They are referred to as extragastrointestinal stromal tumors (EGISTs) and represent around 5-10\% of all GISTs [6]. In this latter case, the tumor itself is not connected to the GI tract and can affect the omentum, mesentery, and retroperitoneum [7]. EGISTs can also originate from the pancreas, but they are extremely uncommon. It is estimated that pancreatic EGISTs account for about $5 \%$ of all EGISTs, with around 30 cases being reported in the literature so far [8].

\section{Aim}

The current case report presents a female patient diagnosed with a rare form of pancreatic head EGIST that infiltrates the descending duodenum and illustrates relevant clinical data and serum parameters, pathological changes depicted on medical imaging methods, histopathology (HP) and immunohistochemistry (IHC) findings, and detailed surgical treatment.

\section{ㅁ Case presentation}

A 53-year-old female patient, with no remarkable personal or family medical history, was admitted to the Department of General Surgery for recent melena, fatigue, weight-loss, and poor overall condition. The clinical examination revealed pale skin and mucous membranes. The digital rectal examination showed black tarry stools suggesting a possible upper GI bleeding. Routine laboratory tests at admission demonstrated moderate anemia $(8.2 \mathrm{~g} / \mathrm{dL})$. The serum values of carbohydrate antigen 19-9 (CA 19-9) and carcinoembryonic antigen (CEA) were within normal limits. The rest of the serum parameters recorded normal values.

Both chest and abdominal radiographs had a normal appearance. Abdominal ultrasonography (US) showed a large hypoechoic mass $(59 / 39 \mathrm{~mm})$ located in the duodenal arch. Afterwards, the patient was sent in for an abdominal double contrast-enhanced (oral and intravenous contrast) computed tomography (CT), which revealed a heterogeneous tumoral mass affecting the head of the pancreas and the second part of the duodenum measuring $83 / 70 / 70 \mathrm{~mm}$, with

This is an open-access article distributed under the terms of a Creative Commons Attribution-NonCommercial-ShareAlike 4.0 International Public License, which permits unrestricted use, adaptation, distribution and reproduction in any medium, non-commercially, provided the new creations are licensed under identical terms as the original work and the original work is properly cited. 
well-defined margins and intralesional areas of hemorrhage and necrosis (Figure 1, A-C). Also, the common bile duct measured $11 \mathrm{~mm}$ in size, and the maximum diameter of the Wirsung duct was $5 \mathrm{~mm}$. Next, the patient underwent an esogastroduodenoscopy and a colonoscopy. In the second part of the duodenum, the major duodenal papilla and the mucosa surrounding it had a tumoral, ulcerated appearance. Therefore, multiple biopsies were performed at this level. After evaluating the prelevated tissue samples, the HP report indicated the presence of spindle cells and numerous atypical mitoses which were suggestive for a malignant mesenchymal tumor.

After presenting the possible benefits and downsides of an exploratory laparotomy, the patient agreed to undergo this procedure. Upon inspection, a large pancreatic head tumor invading the descending duodenum was encountered with no associated vascular invasion or macroscopic liver metastases. The medical team opted for pancreaticoduodenectomy (Whipple procedure) with end-to-side pancreaticojejunostomy ("duct to mucosa"), end-to-side hepatojejunostomy, and gastrojejunostomy.

Grossly, the surgically resected specimen was a wellcircumscribed, partially encapsulated solid mass, measuring $80 / 70 / 50 \mathrm{~mm}$, with focal intratumoral areas of hemorrhage and necrosis. Also, the tumor extended to the descending duodenum wall, infiltrating, and ulcerating this area on approximately 30/30 mm (Figure 2, A-E). Resection margins and regional lymph nodes indicated no signs of tumoral proliferation. The microscopic examination revealed a neoplastic proliferation of spindle cells. The mitotic count was $>5$ per 50 high-power fields (HPFs). IHC revealed strong positivity for c-KIT [cluster of differentiation 117 (CD117)], discovered on GIST 1 (DOG1), but negativity for cluster of differentiation 34 (CD34), desmin, and muscle- specific actin (MSA). The Ki67 labeling index was 40\% (Figure 3, A-E; Figure 4, A and B).

Based on the HP and IHC findings, the surgically resected specimen was classified as an EGIST originating from the pancreas and associated a high risk of malignancy. Both clinical and radioimaging findings did not indicate the presence of another primary tumor.

The postoperative evolution of the patient was uneventful and adjuvant Imatinib mesylate treatment was started. The follow-up was scheduled at six months after surgery and revealed a favorable evolution (Figure 5, A-C).

\section{ㅁ Discussions}

The exact worldwide incidence of GIST still remains unknown, mainly due to the fact that this disease is underdiagnosed or misdiagnosed in many parts of the world. Recent estimates indicate that around 10-20 per 1000000 people, per year develop GISTs worldwide [9-11]. This type of tumor seems to affect people of all ages and does not seem to be greatly influenced by the patient's gender. Usually, GISTs seem to target people over 60 years of age. Moreover, recent studies indicate that less than $3 \%$ of all GISTs affect children $[12,13]$.

In over two-thirds of patients, GISTs generate nonspecific signs and symptoms like bleeding, abdominal discomfort or pain, obstructive jaundice, dysphagia or fatigue. Not infrequently, estimates range from 5-20\% of cases, pancreatic tumors can evolve with the appearance of bone metastases when, to improve the quality of life, comfort osteosynthesis must be performed. At the same time, these patients may suffer major complications caused by ruptured osteosynthetic materials, being known that pathological bone fracture does not heal, and the material will suffer stress degradation over time [14].
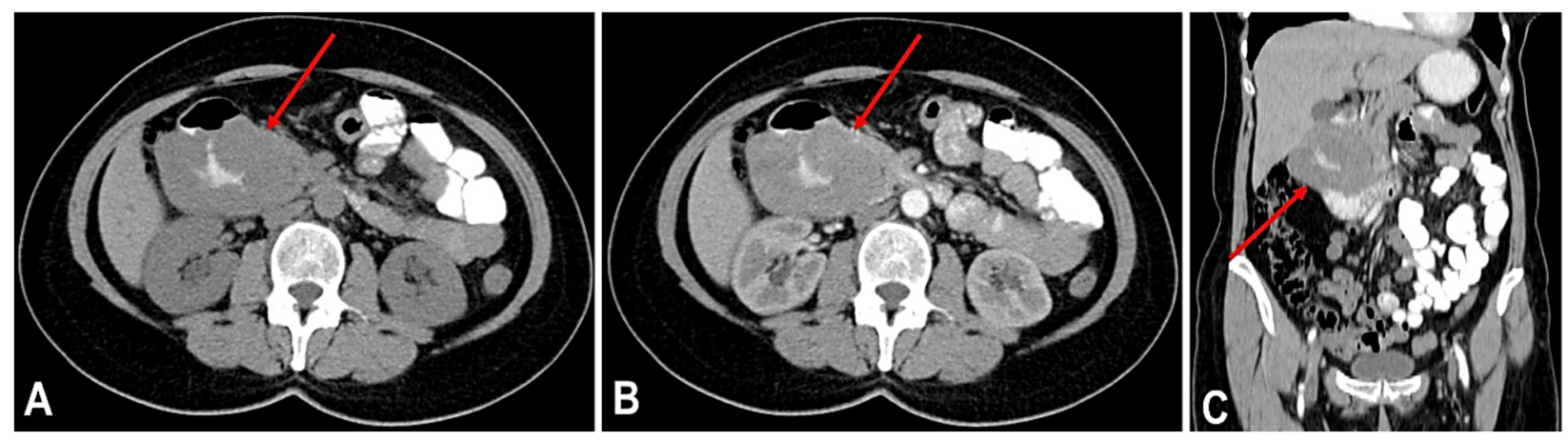

Figure 1 - The CT examination performed before surgery revealed a large tumoral mass affecting the head of the pancreas and the descending duodenum: (A) Oral contrast, no intravenous contrast, axial plane; (B) Postcontrast sequence, arterial phase, oral and intravenous contrast, axial plane; (C) Postcontrast sequence, arterial phase, oral and intravenous contrast, coronal plane. CT: Computed tomography.
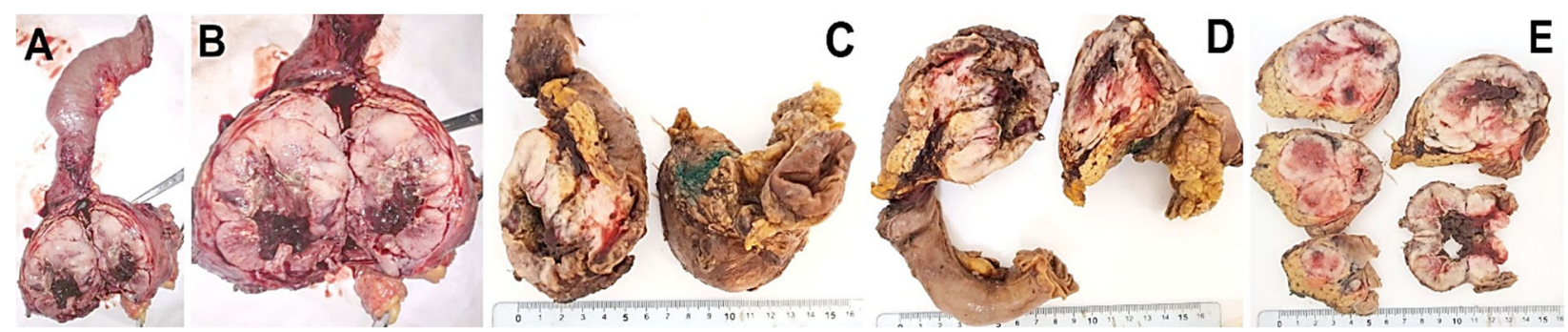

Figure 2 - (A-E) The macroscopic appearance of the surgically resected specimen: a well-circumscribed, partially encapsulated solid mass, measuring $80 / 70 / 50 \mathrm{~mm}$, with focal intratumoral areas of hemorrhage and necrosis affecting the pancreatic head and the descending duodenum. 

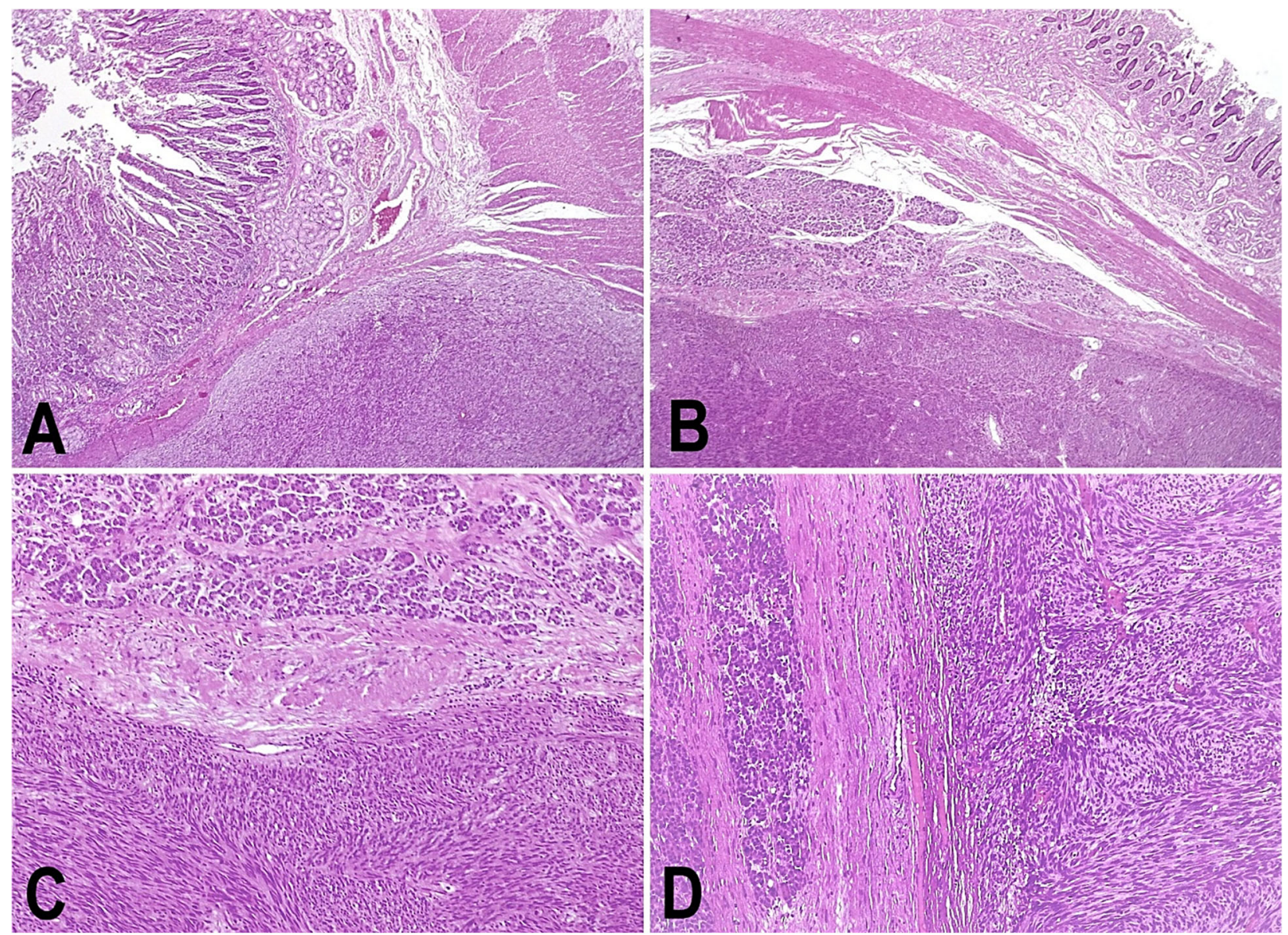

Figure 3 - Pancreatic GIST infiltrating the descending duodenum: (A) Duodenal wall and tumor; (B) Duodenal wall, pancreatic tissue, and tumor; (C) Pancreatic tissue (upper half) and tumor (lower half) (100x); (D) Pancreatic tissue and tumor proliferation; (E) Tumor proliferation, increased mitotic count. $\mathrm{HE}$ staining: $(A$ and $B) \times 25$; (C and D) $\times 100 ;(E) \times 400$. GIST: Gastrointestinal stromal tumor; HE: Hematoxylin-Eosin.
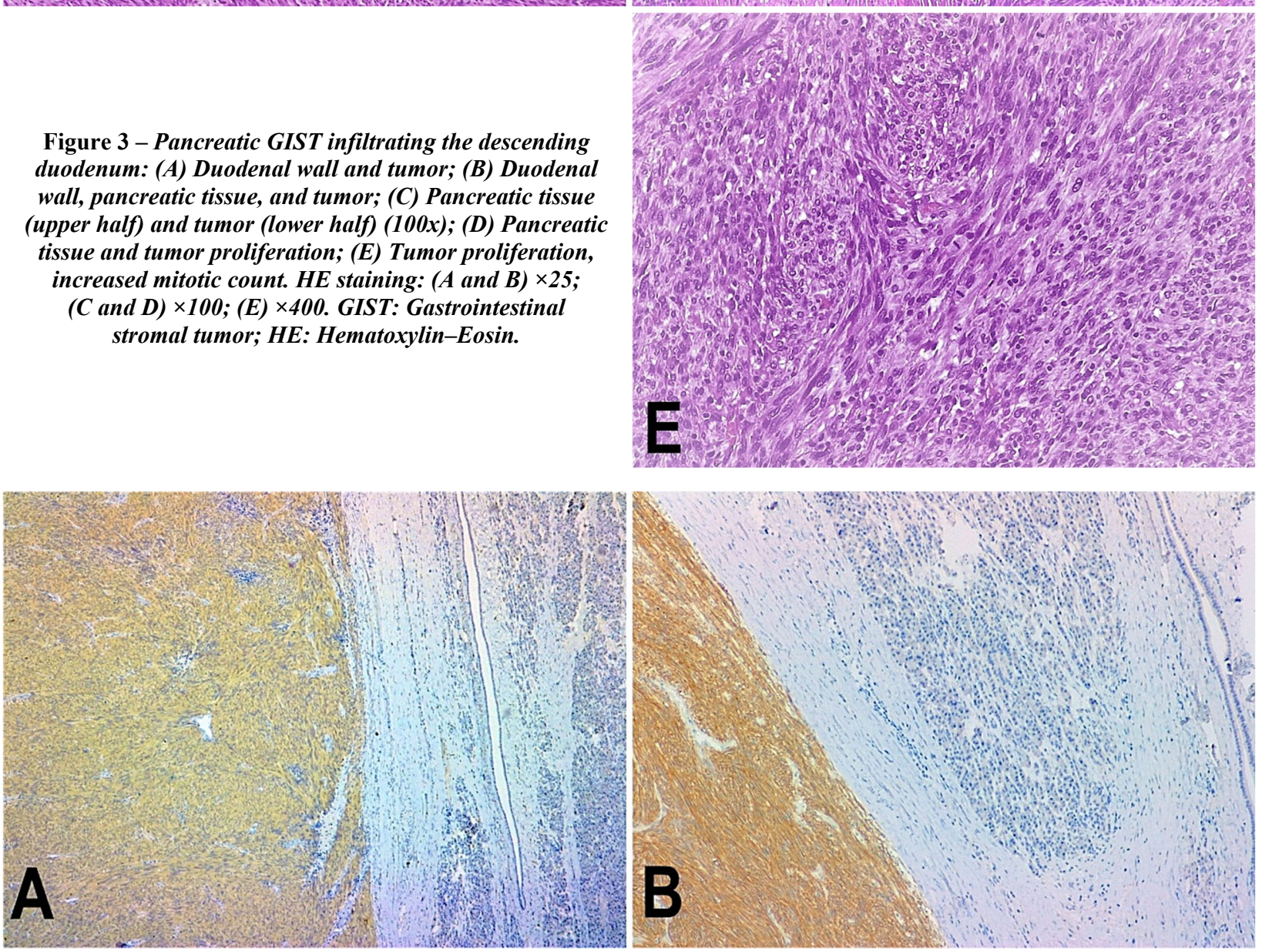

Figure 4 - Immunohistochemistry (×100) revealed positivity for both CD117 (A) and DOG1 (B) immunomarkers. CD117: Cluster of differentiation 117; DOG1: Discovered on GIST 1; GIST: Gastrointestinal stromal tumor. 

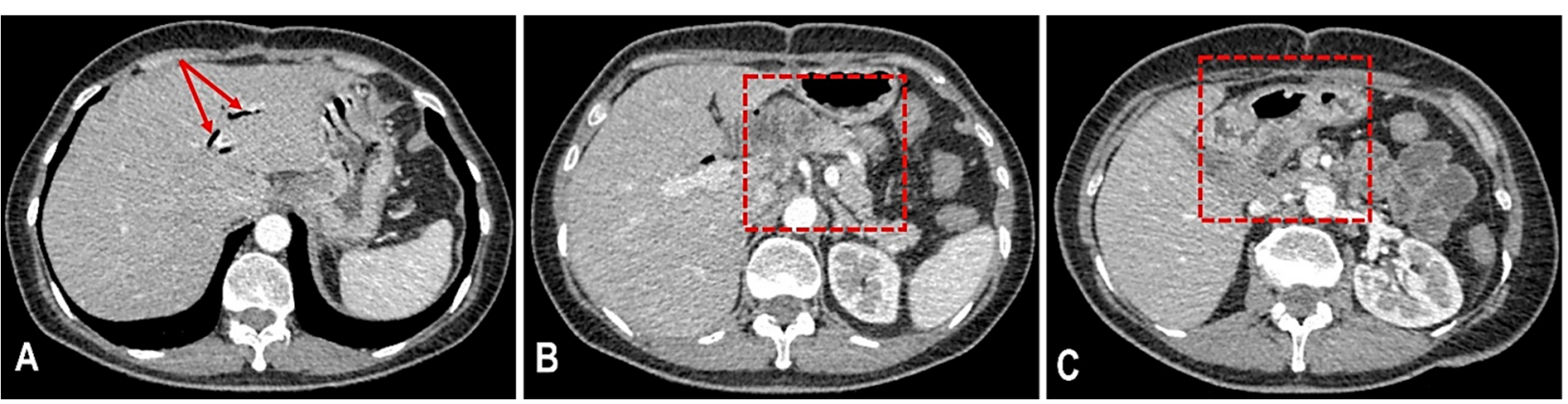

Figure 5 - The follow-up CT examination performed at six months after surgery revealed pneumobilia (A) after pancreaticoduodenectomy using Whipple procedure with end-to-side pancreaticojejunostomy (B), end-to-side hepatojejunostomy, and gastrojejunostomy (C). CT: Computed tomography.

The intensity and variability of these symptoms is directly related to the location and size of the tumor inside the pancreas. Up to $20 \%$ of patients affected by GISTs remain asymptomatic and around $10 \%$ are discovered during autopsy [15-17].

Radiology and medical imaging play a central part in evaluating pancreatic tumors. US, CT, magnetic resonance imaging (MRI) and endoscopic ultrasound (EUS) are only some of the most common techniques that provide important medical imaging data regarding the tumor size and location, distant metastases, and invasion of adjacent anatomical structures, without being able to clearly indicate the histological type of the tumor itself [18, 19], often making the differential diagnosis with other rare pathologies [20]. In addition, magnetic resonance spectroscopy (MRS) is another modern medical imaging method which can be used to detect intratumoral peak levels of certain metabolites [21]. For example, a prostate EGIST described in the current literature associated elevated citrate peak levels in the affected prostate area [22].

GISTs are usually diagnosed based on the molecular traits, HP, and IHC data. HP results can differentiate three types of GISTs: ( $i$ ) spindle type; (ii) epithelioid type; (iii) mixed type. The spindle type is the most frequently encountered in pancreatic EGISTs [18].

Regarding treatment possibilities, surgery still remains the most viable option. Pancreatic head tumors are usually removed through pancreaticoduodenectomy (Whipple procedure) while distal pancreatectomy is used for resecting tumors that affect the pancreatic tail [23]. In addition, using Imatinib as a neoadjuvant and adjuvant therapy is associated with an increased survival rate and a lower rate of recurrence [24]. Treatment of cancer patients with other therapies, may result in significant bone loss as well even in young patients and not infrequently associations with other significant conditions $[25,26]$.

Beltrame et al. [27] collected relevant clinical and pathological data from 21 pancreatic EGISTs described in the literature. The patients' mean age was 55 years and ranged from 31 to 84 years. Both genders were almost equally affected (11 women, 10 men). The pancreatic head and/or uncinate process were affected in slightly over half of all examined patients. IHC revealed CD117(+) and CD34(+) immunomarkers in 18 (85.71\%) and $12(57.14 \%)$ patients, respectively [27].

\section{ㅁ Conclusions}

The current report presents an extremely rare case of pancreatic EGIST encountered in a 53-year-old woman with no remarkable personal or family medical history. Surgical resection of the pancreatic head tumor through pancreaticoduodenectomy using Whipple procedure combined with negative resection margins and adjuvant Imatinib mesylate treatment led to a favorable postoperative evolution. The follow-up at six months after surgery did not reveal any malignant changes.

\section{Conflict of interests}

No conflict of interests to declare.

\section{References}

[1] Sanchez-Hidalgo JM, Duran-Martinez M, Molero-Payan R, Rufian-Peña S, Arjona-Sanchez A, Casado-Adam A, CosanoAlvarez A, Briceño-Delgado J. Gastrointestinal stromal tumors: a multidisciplinary challenge. World J Gastroenterol, 2018, 24(18):1925-1941. https://doi.org/10.3748/wjg.v24.i18.1925 PMID: 29760538 PMCID: PMC5949708

[2] Søreide K, Sandvik OM, Søreide JA, Giljaca V, Jureckova A, Bulusu VR. Global epidemiology of gastrointestinal stromal tumours (GIST): a systematic review of population-based cohort studies. Cancer Epidemiol, 2016, 40:39-46. https://doi.org/ 10.1016/j.canep.2015.10.031 PMID: 26618334

[3] Nilsson B, Bümming P, Meis-Kindblom JM, Odén A, Dortok A, Gustavsson B, Sablinska K, Kindblom LG. Gastrointestinal stromal tumors: the incidence, prevalence, clinical course, and prognostication in the preimatinib mesylate era - a population-based study in western Sweden. Cancer, 2005, 103(4):821-829. https://doi.org/10.1002/cncr.20862 PMID: 15648083

[4] Harlan LC, Eisenstein J, Russell MC, Stevens JL, Cardona K. Gastrointestinal stromal tumors: treatment patterns of a population-based sample. J Surg Oncol, 2015, 111(6):702707. https://doi.org/10.1002/jso.23879 PMID: 25900896

[5] DeMatteo RP, Lewis JJ, Leung D, Mudan SS, Woodruff JM, Brennan MF. Two hundred gastrointestinal stromal tumors: recurrence patterns and prognostic factors for survival. Ann Surg, 2000, 231(1):51-58. https://doi.org/10.1097/00000658200001000-00008 PMID: 10636102 PMCID: PMC1420965

[6] Du CY, Shi YQ, Zhou Y, Fu H, Zhao G. The analysis of status and clinical implication of KIT and PDGFRA mutations in gastrointestinal stromal tumor (GIST). J Surg Oncol, 2008, 98(3): 175-178. https://doi.org/10.1002/jso.21104 PMID: 18618605

[7] Reith JD, Goldblum JR, Lyles RH, Weiss SW. Extragastrointestinal (soft tissue) stromal tumors: an analysis of 48 cases with emphasis on histologic predictors of outcome. Mod Pathol, 2000, 13(5):577-585. https://doi.org/10.1038/modpathol.388 0099 PMID: 10824931

[8] Akbulut S, Yavuz R, Otan E, Hatipoglu S. Pancreatic extragastrointestinal stromal tumor: a case report and comprehensive literature review. World J Gastrointest Surg, 2014, 6(9):175182. https://doi.org/10.4240/wjgs.v6.i9.175 PMID: 25276287 PMCID: PMC4176778

[9] Kim KM, Kang DW, Moon WS, Park JB, Park CK, Sohn JH, Jeong JS, Cho MY, Jin SY, Choi JS, Kang DY; Gastrointestinal Stromal Tumor Committee; Korean Gastrointestinal Pathology 
Study Group. Gastrointestinal stromal tumors in Koreans: it's incidence and the clinical, pathologic and immunohistochemical findings. J Korean Med Sci, 2005, 20(6):977-984. https://doi. org/10.3346/jkms.2005.20.6.977 PMID: 16361808 PMCID: PMC2779330

[10] Tryggvason G, Gíslason HG, Magnússon MK, Jónasson JG. Gastrointestinal stromal tumors in Iceland, 1990-2003: the Icelandic GIST study, a population-based incidence and pathologic risk stratification study. Int J Cancer, 2005, 117(2): 289-293. https://doi.org/10.1002/ijc.21167 PMID: 15900576

[11] Goettsch WG, Bos SD, Breekveldt-Postma N, Casparie M, Herings RMC, Hogendoorn PCW. Incidence of gastrointestinal stromal tumours is underestimated: results of a nation-wide study. Eur J Cancer, 2005, 41(18):2868-2872. https://doi.org/ 10.1016/j.ejca.2005.09.009 PMID: 16293410

[12] Tran T, Davila JA, El-Serag HB. The epidemiology of malignant gastrointestinal stromal tumors: an analysis of 1,458 cases from 1992 to 2000 . Am J Gastroenterol, 2005, 100(1):162-168. https:// doi.org/10.1111/j.1572-0241.2005.40709.x PMID: 15654796

[13] Miettinen M, Sobin LH, Lasota J. Gastrointestinal stromal tumors of the stomach: a clinicopathologic, immunohistochemical, and molecular genetic study of 1765 cases with long-term follow-up. Am J Surg Pathol, 2005, 29(1):52-68. https://doi. org/10.1097/01.pas.0000146010.92933.de PMID: 15613856

[14] Nica M, Cretu B, Ene D, Antoniac I, Gheorghita D, Ene R. Failure analysis of retrieved osteosynthesis implants. Materials (Basel), 2020, 13(5):1201. https://doi.org/10.3390/ma130512 01 PMID: 32155981 PMCID: PMC7085058

[15] Soufi M, Bouziane M, Massrouri R, Chad B. Pancreatic GIST with pancreas divisum: a new entity. Int J Surg Case Rep, 2013, 4(1):68-71. https://doi.org/10.1016/j.ijscr.2012.09.007 PMID: 23123418 PMCID: PMC3537933

[16] Čečka F, Jon B, Ferko A, Šubrt Z, Nikolov DH, Tyčová V. Longterm survival of a patient after resection of a gastrointestinal stromal tumor arising from the pancreas. Hepatobiliary Pancreat Dis Int, 2011, 10(3):330-332. https://doi.org/10.1016/s14993872(11)60056-8 PMID: 21669581

[17] Fletcher CDM, Berman JJ, Corless C, Gorstein F, Lasota J, Longley BJ, Miettinen M, O'Leary TJ, Remotti H, Rubin BP, Shmookler B, Sobin LH, Weiss SW. Diagnosis of gastrointestinal stromal tumors: a consensus approach. Hum Pathol, 2002, 33(5):459-465. https://doi.org/10.1053/hupa.2002.123545 PMID: 12094370

[18] Elgeidie A, El-Magd ESA, El-Maaty SRA, El-Hawary AK. Pancreatic gastrointestinal stromal tumor: a case report. Int $J$ Surg Case Rep, 2016, 29:67-70. https://doi.org/10.1016/j.ijscr. 2016.08.019 PMID: 27816691 PMCID: PMC5099278
[19] Streba CT, Gîltan AM, Gheonea IA, Demetrian A, Şoimu AV, Săftoiu A, Gruionu G, Gruionu LG. Utility of confocal laser endomicroscopy in pulmonology and lung cancer. Rom J Morphol Embryol, 2016, 57(4):1221-1227. PMID: 28174787

[20] Turculeţ C, Ene D, Georgescu TF, Ciucă E, Vlădăşcău A, lordache F, Beuran M. A rare case of upper digestive hemorrhage due to bleeding duodenal tumor. Chirurgia (Bucharest), 2016, 111(6):505-508. https://doi.org/10.21614/chirurgia.111.6.505 PMID: 28044953

[21] Lăpădat AM, Florescu LM, Manea NC, Gheonea DI, Pirici D, Tudoraşcu DR, Ene R, Gheonea IA. MR spectroscopy of the liver - a reliable non-invasive alternative for evaluating nonalcoholic fatty liver disease. Rom J Morphol Embryol, 2020, 61(1):73-80. https://doi.org/10.47162/RJME.61.1.08 PMID: 32747897 PMCID: PMC7728118

[22] Nguyen Thanh T, Nguyen TTN, Le TB, Le DD, Nguyen VM, Le DK. Extragastrointestinal stromal tumor presenting as an exophytic prostatic mass. Radiol Case Rep, 2020, 15(8):11421148. https://doi.org/10.1016/.radcr.2020.05.003 PMID: 32514326 PMCID: PMC7267684

[23] Florescu LM, Gheonea IA, Ene D, Florescu DN, Braia N, Pirici D, Şandru V, Forţofoiu MC, Ciurea T. An extremely rare case of distal common bile duct adenocarcinoma in a 65-yearold male patient. Rom J Morphol Embryol, 2018, 59(1):297302. PMID: 29940641

[24] Gupta P, Tewari M, Shukla HS. Gastrointestinal stromal tumor. Surg Oncol, 2008, 17(2):129-138. https://doi.org/10.1016/j. suronc.2007.12.002 PMID: 18234489

[25] Popescu D, Ene R, Popescu A, Cîrstoiu M, Sinescu R, Cîrstoiu C. Total hip joint replacement in young male patient with osteoporosis, secondary to hypogonadotropic hypogonadism. Acta Endocrinol (Bucharest), 2015, 11(1):109-113. https://doi.org/10.4183/aeb.2015.109 https://acta-endo.ro/2015/ numarul1/fulltext/109-113\%20D.\%20Popescu.pdf

[26] Romosan AM, Dehelean L, Romosan RS, Andor M, Bredicean AC, Simu MA. Affective theory of mind in Parkinson's disease: the effect of cognitive performance. Neuropsychiatr Dis Treat, 2019, 15:2521-2535. https://doi.org/10.2147/NDT.S219288 PMID: 31564879 PMCID: PMC6722434

[27] Beltrame V, Gruppo M, Pastorelli D, Pizzi S, Merigliano S, Sperti C. Extra-gastrointestinal stromal tumor of the pancreas: case report and review of the literature. World J Surg Oncol, 2014, 12:105. https://doi.org/10.1186/1477-7819-12-105 PMID: 24755359 PMCID: PMC4000617

\section{Corresponding authors}

Lucian Mihai Florescu, MD, PhD, Department of Radiology and Medical Imaging, University of Medicine and Pharmacy of Craiova, 2 Petru Rareş Street, 200349 Craiova, Romania; Phone +40723-295 696, e-mail: lucian.florescu@umfcv.ro Răzvan Ene, MD, PhD, Department of Orthopedics and Traumatology, Emergency Clinical Hospital, 8 Floreasca Avenue, 014452 Bucharest, Romania; Phone +40740-082 338, e-mail: razvan77ene@yahoo.com 